\title{
ESTRATEGIAS DE DOCENTES EN CONTRA DE LA VIOLENCIA ESCOLAR EN ESCUELAS PRIMARIAS Y SECUNDARIAS DE COLIMA, MÉXICO
}

\section{Teachers' strategies and suggestions against school violence in primary and secondary schools from Colima, Mexico}

\author{
Antonio Gómez-Nashiki \\ Facultad de Pedagogía de la Universidad de Colima (Colima, México) \\ Correo-e: gnashiki@ucol.mx
}

Recepción: I4 de junio de 2015

Envío a informantes: 16 de junio de 2015

Fecha de aceptación definitiva: 22 de diciembre de 2015

Resumen: El artículo analiza la forma en que la violencia escolar se produce y reproduce en la institución educativa y las estrategias exitosas que los docentes de distintos municipios de Colima han implementado para afrontarla. Se entrevistó a I4 docentes de escuelas primarias públicas y 35 de escuelas públicas y privadas de educación secundaria. Entre las principales conclusiones están, en primer lugar, las condiciones en que desarrollan su práctica: el malestar que experimentan en la institución ante los distintos tipos de violencia, ya sea entre los estudiantes, y en algunos casos hacia ellos; la falta de herramientas para saber cómo resolver estos problemas; la necesidad de tomar cursos de capacitación y conocer estrategias de intervención acordes con sus necesidades y contexto, así como el escaso apoyo de los padres de familia para atender estas situaciones; $\mathrm{y}$, en segundo lugar, se exponen las opiniones, sugerencias y recursos que de manera intuitiva y creativa utilizan los docentes cotidianamente en las aulas.

PALABRAS ClAve: Estrategias; violencia escolar; escuela primaria; escuela secundaria; práctica docente; México.

АвsтRAст: This article analyzes the way about school violence is produced and reproduced into an educational institution and how teachers successful strategies have applied to face them up in different municipalities in Colima. I4 teachers from elementary public schools and 35 teachers from public and private high school level were interviewed. Among the main conclusions were firstly, the conditions where they have their practice: the discomfort they experienced into the institution under many ways 
of violence, they could be between students and some cases to teachers too; the lack of tools to know how to solve these problems; the need to take training courses and know intervention strategies according with their needs and context, if were necessary get the support from students' parents to attend the situations; secondly opinions are exposed, suggestions and resources in an intuitive and creative way, teachers use daily in the classrooms.

KEY WORDS: strategies; school violence; elementary school; high school; teacher practice; México.

\section{Presentación}

L

A ViOlenCiA EN LA ESCUEla es un tema que no puede dejarse de lado si lo que se pretende es mejorar la calidad de la educación en México. Actualmente, se hiki, 2005; Gómez-Nashiki, Zurita y Molina, 20II; Furlan y Spitzer, 20ı3) que señalan que su presencia es indiscutible y su atención resulta indispensable para mejorar las condiciones de la vida cotidiana en la escuela.

El combate a la violencia escolar desde las aulas ha sido un tema central en las últimas dos décadas en nuestro país, y en distintas investigaciones se ha demostrado que el peso de la cultura dominante se refleja casi de manera automática, y en algunas se impone a los aprendizajes y conocimientos que se imparten en la escuela (Willis, 1988), por lo que en su tratamiento el papel del maestro es crucial, así como los recursos que utilice para enfrentarla.

\section{Ejes conceptuales}

\section{I. Violencia escolar}

Se refiere a aquella que se ejerce de forma consciente y voluntaria, y no a la estatal, animal o la patológica, por tanto, la violencia en la escuela es un recurso de poder que utilizan los distintos sujetos ante situaciones específicas de la siguiente manera: a) Del maestro hacia los alumnos, como un recurso de poder para hacer valer su autoridad y mantener el control en el aula; b) Entre los alumnos forma parte de una fuerza abierta u oculta, con el fin de obtener de un individuo o de un grupo algo que no quiere consentir libremente; c) De los alumnos hacia el docente es un recurso de poder que busca restarle autoridad, cuestionando su trabajo y las disposiciones que adopta, con la finalidad de desestabilizar el control en el aula y lograr legitimidad entre sus compañeros (Gómez-Nashiki, 2005; Gómez-Nashiki, 20I4); d) Para los padres de familia es un cuestionamiento a la autoridad: a la escuela, al docente y a la suya, así como la pérdida del control e información de las acciones que su hijo realiza en la institución -más allá de que sea el agresor o la víctima-, lo que representa consecuencias educativas y sociales negativas que se manifiestan en una inestabilidad en el ámbito familiar y escolar.

El común denominador en todos los casos es que se trata de un proceso que viola la integridad física, social y/o psicológica de una persona o grupo. La violencia escolar, 
ESTRATEGIAS DE DOCENTES EN CONTRA DE LA VIOLENCIA ESCOLAR EN ESCUELAS PRIMARIAS Y SECUNDARIAS DE COLIMA, MÉXICO ANTONIO GÓMEZ-NASHIKI

por lo tanto, se puede presentar en la institución como producto de una dinámica que implica la fuerza física, psicológica o verbal, y puede ser ejercida por cualquiera de los actores involucrados ante situaciones tan disímbolas e inesperadas, de manera explícita u oculta (Gómez-Nashiki, 20I4: II).

\subsection{Cultura y violencia en la escuela}

La cultura de una institución educativa está constituida a partir del cúmulo de conocimientos, técnicas, normas, tradiciones, creencias, valores, expectativas y procedimientos (Pérez-Gómez, 1999; Fernández, 20oI) que tanto la escuela establece como lo que cotidianamente maestros, alumnos, directivos, padres de familia y personal de apoyo esperan y llevan a cabo (Fernández, 20or; Santos Guerra, 2000). La institución como lugar de vida (Kaës, I989) es una arena que se caracteriza por la complejidad inherente que se registra en su seno, que posee una manera de plantear y resolver problemas; una racionalidad intrínseca (Anderson, 1962) que ante determinadas coyunturas y tipos de conflicto se convierte en campo de lucha (Ball, 1989) y que da origen a alianzas, liderazgos, desafíos, luchas por el control y confrontaciones permanentes o momentáneas entre los diferentes grupos y sujetos que comparten fines y propósitos; presentándose en ocasiones aspectos confusos, inextricables, ambiguos, llenos de incertidumbre (Jackson, 20oI). En las constantes disputas que persigue cada sujeto y/o grupo por lograr sus respectivos intereses y proyectos se utilizan distintos recursos de poder y estrategias: amenazas, contraamenazas, coacción, así como los diferentes tipos de violencia: verbal, psicológica, física, sexuada (Gómez-Nashiki, 20I4), con la finalidad de lograr que sus fines y objetivos se cumplan.

\subsection{Práctica docente y estrategia}

La docencia es una actividad que conjunta distintos niveles de complejidad y que implica la toma de decisiones ante situaciones tanto planeadas como inesperadas, producto de la interacción cotidiana. Si bien se asocia con la impartición de contenidos, de saberes y habilidades en un primer momento (Mercado, 2002), muchas investigaciones han dado cuenta de la multiplicidad de aspectos -más allá de los estrictamente formales y académicos-, que se ponen en juego al momento de iniciar la clase cotidianamente como parte del funcionamiento institucional (Pérez, 1999; Jackson, 200I). En donde el papel del maestro adquiere una relevancia tanto por lo que dice verbalmente como corporalmente.

El otro componente clave desde nuestro punto de vista es el conocimiento práctico que posee un docente: los saberes (Mercado, 2002), que va construyendo a cada momento, a partir del ejercicio de su práctica cotidiana, que conceptualizaremos como el conjunto de conocimientos complejos, orientados a la práctica que utilizan activamente para conformar y dirigir el trabajo de la enseñanza (Elbaz, I98I). Investigaciones sobre la práctica docente han mostrado que los profesores no son de ninguna manera meros ejecutores de las teorías o preceptos educativos, como se les ha intentado ver por muchos años, o los simples aplicadores de políticas diseñadas desde los escritorios de las distintas dependencias educativas (Rockwell y Mercado, 2003). 
El trabajo docente enfrenta una serie de imprevistos, lo que se ha denominado incertidumbre de la práctica, es decir, el carácter azaroso al momento de desarrollar su trabajo y en todo momento mantener como prioritaria la enseñanza de los contenidos, independientemente de lo que suceda en el aula o en la institución: una interrupción, atender el llamado de la dirección, informar al supervisor de la planeación semanal, por citar algunos ejemplos.

\subsection{Estrategias docentes}

La aparente rutina de la vida cotidiana (Jackson, 20oI), así como la generación de diversas situaciones entre los integrantes de una institución educativa, sigue siendo una fuente inagotable de prácticas y saberes que aún estamos lejos de comprender completamente. Muchas son las interrogantes que permanecen en torno a la forma en que los maestros transmiten y abordan sus contenidos, de igual manera, de las múltiples acciones y estrategias que siguen y ponen en práctica en el marco de normas, ritos, tradiciones, creencias, roles, antecedentes institucionales, para lograr que sus alumnos respondan a los objetivos y conocimientos que pretenden transmitir.

Los profesores utilizan su conocimiento para estructurar o transformar las situaciones sociales en las que laboran, de alguna manera ponen en juego sus habilidades para hacerlas compatibles con el lugar en donde trabajan. En su conocimiento empírico se puede distinguir un componente rutinario que les ayuda a desenvolverse en las impredecibles e inmediatas situaciones de la práctica docente.

La estrategia constituye una respuesta y proposición para actuar de acuerdo con las circunstancias del momento, se basa en decisiones conscientes que intentan orientar el curso de acción en un contexto determinado (Contreras, 2013), pues de la puesta en marcha y de su constante revisión deriva su éxito. La estrategia es una acción dinámica, por lo tanto, no puede considerarse una norma o un documento (Francés, 2006), sino más bien un planteamiento y una actitud en constante revisión; se considera como una directriz a partir de la cual se pueden generar cambios y adecuaciones durante el proceso mismo de su operación. En otras palabras, es un análisis y un propósito de futuro, donde se integran lo educativo y lo didáctico a través de la práctica del docente. Por esta razón, el concepto de estrategia supone la posibilidad de experimentar o ensayar las acciones y reacciones ante su puesta en marcha (Gómez-Nashiki, 20o8). El sentido de una estrategia no parte sólo de su conocimiento, sino de su adaptación a los acontecimientos; de la operación que en nuestro caso parte de la capacidad del docente para aplicarla y hacer los ajustes que la misma marcha de su aplicación le exijan. Es decir que el conocimiento teórico es insuficiente para enfrentarse a las demandas inciertas y azarosas de la práctica, por lo que el profesor no puede aplicar mecánicamente las reglas o técnicas que conoce, sino que ha de abordar intuitiva y creativamente el problema que surge en el contexto particular de su enseñanza, lo que es el fundamento y origen de las estrategias que aplica el docente.

Las acciones, estrategias y recomendaciones que se mencionan en este trabajo son producto de la práctica cotidiana, de la experiencia adquirida en sus años de servicio, ya sea por haberlas instrumentado en sus clases o por el consejo de compañeros de trabajo. Algunas de las propuestas mencionadas suelen parecer sencillas en primera instancia, sin embargo, son recursos probados y exitosos. 


\section{Metodología}

La investigación se realizó en dos etapas que se centraron en el estudio de las acciones, sugerencias y estrategias que profesores utilizaban en contra de la violencia escolar; la primera incluyó escuelas de educación primaria (estudiantes de 6 a II años) del proyecto: Acciones, estrategias y sugerencias de las docentes de educación básica para combatir la violencia en escuelas de educación primaria en Colima, Programa Integral de Fortalecimiento Institucional, Centro Universitario de Estudios de Género de la Universidad de Colima, 2or2 y la segunda se ocupó de profesores de educación secundaria (estudiantes de I2 a I5 años), del proyecto: Acciones y estrategias que utilizan maestros de educación secundaria para combatir la violencia en escuelas de educación secundaria en Colima, Fondo Ramón Álvarez-Buylla de Aldana, Universidad de Colima, 2013. Ambos proyectos fueron coordinados bajo mi dirección.

Si bien las condiciones de trabajo de los docentes fueron diferentes por el nivel educativo en donde trabajaban, el objetivo común en ambas investigaciones fue: a) Conocer el tipo de estrategias que empleaban los docentes para enfrentar el fenómeno de la violencia escolar. Los objetivos secundarios fueron: b) Analizar la forma en que la violencia se produce y reproduce en planteles de educación primaria y secundaria de los municipios de Colima y c) Caracterizar los niveles de violencia que se presentan en las aulas de escuelas primarias y secundarias, identificando a los principales protagonistas de este tipo de acciones: maestros-alumnos, alumnos-alumnos.

Se seleccionaron escuelas y docentes de educación primaria y secundaria de los municipios con mayor densidad de población y actividad económica de Colima.

TABLA I: Docentes y escuelas primarias públicas

\begin{tabular}{|c|c|}
\hline Docentes & I4 \\
\hline Escuelas & 7 \\
\hline
\end{tabular}

Nota: La muestra estuvo integrada sólo por mujeres.

TABLA 2: Escuelas primarias y municipio

\begin{tabular}{|c|c|c|c|c|c|c|c|}
\hline Municipios & Colima & Manzanillo & Tecomán & $\begin{array}{c}\text { Villa de } \\
\text { Álvarez }\end{array}$ & Comala & Armería & Total \\
\hline Escuelas primarias & $\mathrm{I}$ & $\mathrm{I}$ & $\mathrm{I}$ & 2 & $\mathrm{I}$ & $\mathrm{I}$ & 7 \\
\hline Docentes & 3 & $\mathrm{I}$ & 3 & 3 & 2 & 2 & $\mathrm{I} 4$ \\
\hline
\end{tabular}

Nota: Sólo se visitaron escuelas públicas.

Las escuelas visitadas fueron elegidas en función de sus características, es decir, planteles con más de ıoo alumnos y con varios años de antigüedad.

TABLA 3: Docentes y escuelas secundarias

\begin{tabular}{|c|c|c|c|}
\hline & Públicas & Privadas & Total \\
\hline Escuelas secundarias & 6 & 4 & Io \\
\hline Docentes & 27 & 8 & 35 \\
\hline
\end{tabular}


ESTRATEGIAS DE DOCENTES EN CONTRA DE LA VIOLENCIA ESCOLAR EN ESCUELAS PRIMARIAS Y SECUNDARIAS DE COLIMA, MÉXICO ANTONIO GÓMEZ-NASHIKI

Tabla 4: Docente por tipo de escuela secundaria, sexo y municipio

\begin{tabular}{|c|c|c|c|c|c|c|c|c|c|c|c|c|c|c|}
\hline Escuelas & \multicolumn{3}{|c|}{ Colima } & \multicolumn{3}{|c|}{ Manzanillo } & \multicolumn{3}{|c|}{ Tecomán } & \multicolumn{3}{|c|}{ Villa de Álvarez } & \multicolumn{2}{|c|}{ Total } \\
\hline & \multicolumn{3}{|c|}{ Docentes } & \multicolumn{3}{|c|}{ Docentes } & \multicolumn{3}{|c|}{ Docentes } & \multicolumn{3}{|c|}{ Docentes } & & \\
\hline & & $\mathrm{H}$ & $\mathrm{M}$ & & $\mathrm{H}$ & $\mathrm{M}$ & & $\mathrm{H}$ & M & & $\mathrm{H}$ & $\mathrm{M}$ & $\mathrm{H}$ & $\mathrm{M}$ \\
\hline Públicas & 8 & $\mathrm{I}$ & 7 & 3 & $\mathrm{I}$ & 2 & 2 & $\mathrm{o}$ & 2 & $\mathrm{I} 3$ & 2 & $\mathrm{I} 2$ & 4 & 23 \\
\hline Privadas & 2 & 0 & 2 & 2 & I & I & I & o & I & 4 & I & 2 & 2 & 6 \\
\hline Total & IO & $\mathrm{I}$ & 9 & 5 & 2 & 3 & 3 & $\mathrm{O}$ & 3 & 17 & 3 & $\mathrm{I} 4$ & 6 & 29 \\
\hline
\end{tabular}

El tipo de muestra para esta investigación fue no probabilística, porque se buscaba información profunda y detallada, y no cantidad ni estandarización. La elección de los sujetos obedeció a características propias de la investigación, es decir, docentes que promovieron y pusieron en marcha exitosamente estrategias para afrontar la violencia.

Se explicaron a los docentes los objetivos del proyecto y se pidió su autorización para grabar los testimonios para posteriormente publicarlos. Se realizaron 35 entrevistas y se les informó que sus nombres no aparecerían en el trabajo, pues lo que importaba era el hecho y la narrativa de los acontecimientos. En todos los casos, los docentes estuvieron de acuerdo y se mostraron dispuestos a colaborar.

Las entrevistas se llevaron a cabo en las respectivas instituciones, la primera etapa en 2012 y la segunda en 2013, y se plantearon como un diálogo con una parte semiestructurada (Cohen, Manion y Morrison, 20II: 4IO), a partir de un guion. Los temas que se abordaron en las entrevistas fueron: a) Los años de servicio; b) Valoración de los planteles educativos en donde han trabajado; c) Experiencias en temas y conflictos con alumnos; d) Experiencias relacionadas con la violencia escolar, y e) Las estrategias, acciones y recomendaciones que han desarrollado para poder atender este fenómeno desde el ámbito de acción en donde les toca directamente intervenir: la escuela y el aula.

Las entrevistas fueron transcritas en su totalidad y sometidas a un proceso de análisis que consistió en lo siguiente: se diseñó un mapa conceptual para cada entrevista y en cada una se señalaron con distintos colores las frases o palabras clave identificadas en la narrativa de los docentes y que se vinculaban con el objeto de la investigación. A partir del mapa conceptual de cada entrevista se diseñó una matriz de las precategorías con mayor frecuencia en el discurso de los docentes -los colores que más predominaban-, donde, a partir de la exposición textual del docente, se contrastaron los diferentes puntos de vista, es decir, se tomaron sucesivamente diferentes segmentos de información para ver con qué categorías se podían relacionar (Hammersley y Atkinson, 1994: 197). El siguiente paso fue la triangulación, que consistió entre la comparación de los relatos de los diferentes participantes y posteriormente con los conceptos revisados en la teoría vinculados al objeto de investigación. De esta manera, se obtuvieron las categorías definitivas que se desarrollaron a lo largo de la investigación (Hammersley y Atkinson, 1994: 216).

Se utilizó la descripción densa (Geertz, 2006: 19) como una herramienta metodológica que ayudó a dar cuenta de lo acontecido en profundidad en una institución y de los sujetos que la integran, lo que obligó a trabajar con múltiples episodios y relatos que van más allá de una descripción lineal, pues se trató de «darles vida» y poner en juego los distintos elementos que rodean a los sujetos involucrados en el relato. $\mathrm{Na}$ rrar, en este sentido, sirvió para organizar los diversos argumentos, interacciones y juicios que expresaron los sujetos de análisis y sistematizarlos de una manera legible y razonada (Ricoeur, 2007). 


\section{ESTRATEGIAS DE DOCENTES EN CONTRA DE LA VIOLENCIA ESCOLAR EN ESCUELAS PRIMARIAS Y SECUNDARIAS DE COLIMA, MÉXICO ANTONIO GÓMEZ-NASHIKI}

CuAdro i: Discursos de los docentes, precategorías y las categorías finales

\begin{tabular}{l}
\hline Discursos \\
\hline Física: \\
- Todos los días hay peleas. \\
- No saben cómo tratarse más que a puros golpes. \\
- Hombres y mujeres se golpean igual. \\
- Te descuidas y ya están aventándose. \\
- Las niñas se ponen al brinco y unas son más pe- \\
gonas. \\
- Tenía un niño que en cuanto me volteaba escu- \\
pía a los niños, los golpeaba. \\
- Hay maestros que con el gis, borrador y hasta \\
con los libros les dan a los alumnos. \\
- Le dio trancazos a una grandota y la grandota le \\
dio un golpazo en la cabeza, ¡hasta lo tiró! \\
- Me ha tocado que aquí en pleno salón se han \\
agarrado a golpes. \\
\hline
\end{tabular}

Verbal:

- Se burlan de sus compañeros.

- Se ponen apodos.

- Parecen gallitos de pelea

- Se hablan con puras groserías.

- La madre llegó con una actitud desafiante [...], muy agresiva hacia la escuela y hacia la institución $[\ldots .$.$] , a veces con palabras altisonantes se dirigen.$

Psicológica:

- En sus casas nadie les enseña cómo se deben pedir las cosas, los maltratan y los ofenden.

- Se están amenazando todo el tiempo.

- Las niñas ya se cansaron de sufrir burlas y desprecios, se ponen al tú por tú a los niños y a éstos no les gusta que eso pase, porque ya no se dejan [...], resulta que por defender sus derechos sufren más violencia.

- No hay mejor dato que el trabajo cotidiano, ahí te puedes dar cuenta de que un maestro regaña, grita o pega.

- Deberían poner a más maestros, no que uno con grupos de 25 y hasta 35 jóvenes se vuelve una loca por momentos, y tratas de dar la clase y no se puede.

Precategorías
Los alumnos:
- Se atacan con distintos objetos (lápiz, pluma, cua-
derno, palo, etc.).
- Cualquier parte del cuerpo es objeto de agresión.
- Destrozar las pertenencias de compañeros.
- Robar las pertenencias.

CATEgorías

Violencia escolar

Los alumnos:

Se alburean (hablan en doble sentido con connotaciones sexuales).

- Se ponen apodos, humillan, ridiculizan e insultan frecuentemente.

- Caricaturizan a compañeros y maestros.

Los alumnos:

- Maltratan recurrentemente a determinados alumnos.

- Se burlan de las niñas.

- Chantajean, critican e ignorar a determinados alumnos.

- Siempre una más batalla con los latosos, y los que se portan bien son los que menos necesitan [...].

- Yo la verdad a unos alumnos los veo muy preocupados por cumplir, unos cuántos jeh!, pero otros de plano, no.

- Lo malo es que no hay tiempo, aquí andas apenas entrando a clase y ya te tienes que salir, hacen falta estos espacios para que los alumnos se puedan expresar libremente.

- Nomás están esperando a que uno se equivoque al leer o al hacer una operación para empezarse a burlar, pero les digo que eso no es importante, trato de que eso que dicen no lo tomen de pretexto para empezar a pelearse.

- Yo sí creo que hay mucha violencia, que hay unos alumnos más canijos que otros.

Los docentes:

- Señalan un clima desfavorable en el aula.

- Son frecuentes los conflictos todos los días en el aula.

- Pierden mucho tiempo en los llamados al control y al orden.

- Manifiestan sentimientos de inseguridad.

- Señalan el escaso apoyo por parte de los padres.

- Tienen problemas para manejar los conflictos en el aula.

- Solicitan capacitación para el manejo de conflictos.

- Reciben por parte de los alumnos cuestionamientos sobre su forma de enseñar.

- No cuentan con espacios para comunicarse con los alumnos. 


\begin{tabular}{|c|c|c|}
\hline Discursos & Precategorías & Categorías \\
\hline $\begin{array}{l}\text { - Hay unos alumnos más canijos que otros. } \\
\text { - Yo no tolero el maltrato a las mujeres, y es que } \\
\text { a mí me maltrataba mi marido hasta que lo dejé } \\
\text { [...] sé que hay mucho de esto en casa de los } \\
\text { niños, pero aquí no, jeso sí que no! } \\
\text { - Yo creo que el verdadero problema está en que } \\
\text { los muchachos tienen muchos, pero muchos } \\
\text { problemas de atención, van cargando muchos } \\
\text { problemas, muchos traumas y en su casa ni los } \\
\text { pelan, ni les hacen caso. } \\
\text { - La violencia está en esto que te digo, todo mun- } \\
\text { do anda igual y la secundaria no les da espacio } \\
\text { para hablar de cosas para su vida. } \\
\text { - Hace falta educación de sus papás [...] te das } \\
\text { cuenta porque cuando hablas con los papás en } \\
\text { una junta o porque los llamas, algunos no saben } \\
\text { más que ofender a su hijo delante de mí. } \\
\text { - Hay historias muy tristes [...] te puedo decir } \\
\text { que sí sirve, y lo único que piden es respeto, } \\
\text { sí respeto es lo que todos buscan, pero muchas } \\
\text { veces, no los oímos! } \\
\text { - Es que se les pega lo de portarse mal, como que } \\
\text { se ponen de acuerdo. }\end{array}$ & $\begin{array}{l}\text { La institución: } \\
\text { - Hay grupos de alumnos que se quejan de la escuela } \\
\text { y de los maestros. } \\
\text { - Crítica al docente y su forma de enseñar. } \\
\text { - Patrones sexistas de los alumnos hacia sus compa- } \\
\text { ñeras. } \\
\text { - Nula comunicación escuela y familia. } \\
\text { - Escasa valoración de los padres a la escuela y la en- } \\
\text { señanza. }\end{array}$ & Cultura escolar \\
\hline
\end{tabular}

- Se necesita mucha plática con los muchachos [...]

- Es necesario conocer el problema de cerca y

Acciones docentes:

Estrategia saber qué les molesta, pero con maestros de aquí de la Secretaría y padres.

- Sí es necesario que los padres entren a la es-

- Fomentar la comunicación con padres y alumnos.

Contratar personal especializado.

- Brindar apoyo al docente en el aula.

- Hacer reuniones con temas de interés para los jóvenes. cuela [...], no es fácil tenerlos aquí, y eso es un gran reto.

- Había un problema y luego, luego lo atendían, la psicóloga hablaba con los padres y todo era muy rápido.

- Hay muchos alumnos de la normal y de pedagogía que les serviría estar con un maestro en servicio.

- Un día a la semana es necesario reunirse para platicar con los alumnos y abordar lo que se tenga que decir, iquién se portó mal?, ¿quién salió castigado?, ‘a quién lo están molestando?, ¿quién se siente con miedo?

- Yo creo que en esta edad hay que entrarles por la buena, por la parte de la reflexión, de la buena onda, porque así no te metes en problemas, ponerles videos con mensaje.

- Yo les pido que a mitad de año, cuando ya se conocen, que hagan una lista de lo que les gusta, de cómo les gustaría que los trataran y lo malo que les pasa.

- Muchos traen problemas de su casa y nadie les ayuda, por eso, que lo saquen a deportes [...], corriendo, saltando, pero que se muevan [...], porque es la única manera [...] que se controlen, pero la verdad como está la secundaria no creo que lo hagan, los atiborran de materias $[\ldots]$.

Conocer más a los alumnos.

- Contar con buenos cursos presenciales de capacitación.

Fomentar el deporte entre los alumnos.

Ayudar a los alumnos a expresar lo que les gusta y molesta.

Fomentar valores de convivencia cotidianamente.

- Promover la equidad de género. 


\begin{tabular}{l}
\hline Discursos \\
\hline - Yo sí cambiaría a los prefectos por personas que \\
sepan de psicología, y de cómo atender a los \\
alumnos, pero ya ve, en las escuelas hay mucha \\
gente que no hace nada y ahí sigue. \\
- Los viernes hacemos el aseo, y eso sí, a propósito \\
pongo a los niños a trapear, limpiar y lavar los \\
trapos y trastos [...], esto no tiene mucha impor- \\
tancia dirás, pero sí la tiene [...], para que se den \\
cuenta de que no son cosa de mujeres solamente. \\
- Prohibido tocar a una mujer, se tienen que en- \\
señar a respetar, si no es aquí jen dónde? [...] \\
el castigo es hablar con los padres y si no pido \\
expulsión de mi grupo [...]. \\
- No tengo nada en contra de los cursos, son \\
buenos y eso es algo que debería de apoyarse, \\
pero me ha tocado que va un representante y lo \\
que [nos] explica no es lo mismo. \\
- Yo ya dije que venga otra compañera y que \\
ayude a lo administrativo, y a apoyar a los que \\
se van quedando atrás. \\
- No te niego que uno se harta a veces, yo por eso \\
digo que es mejor detectar desde un principio \\
a aquellos alumnos que son más latosos, más \\
inquietos y te los sientas junto a ti y los estás \\
vigilando, a mí me ha servido, no hay otra, por- \\
que de verdad se contagia eso de portarse mal. \\
- Había un joven [...], se podía acercar a los \\
alumnos y nos contaba de sus preocupaciones, \\
eso servía de mucho [...]. \\
- Yo sí cambiaría a los prefectos por personas \\
que sepan de psicología [...], en las escuelas hay \\
mucha gente que no hace nada y ahí sigue. \\
- Con un apoyo de otra compañera cambiaría, así \\
si los alumnos van a poner atención, se guarda- \\
ría el orden.
\end{tabular}

PRECATEgorías

CATEgORÍAs

Nota: En la columna de la izquierda se colocaron fragmentos del discurso de los docentes, en la del centro los elementos que conforman las precategorías y en la columna de la derecha las categorías definitivas utilizadas en el trabajo. Es importante mencionar que en un acontecimiento se pueden dar dos o más acciones simultáneamente, por ejemplo, durante una pelea se puede registrar violencia física y psicológica; una combinatoria en la que en distinto orden pueden mezclarse varios tipos de situaciones. La parte del esquema sobre la violencia física, verbal y psicológica se elaboró a partir la idea de Welzer-Lang (2007) y se complementó con registros propios.

\section{Hallazgos}

Las aportaciones de los profesores registradas en este trabajo surgen del conocimiento, experiencia y práctica cotidiana en las aulas. Si bien las estrategias pueden estar asociadas a control de grupo, enseñanza y aprendizaje de contenidos, lo que privilegiamos fue aquellas recomendaciones, estrategias y sugerencias encaminadas a prevenir y combatir la violencia escolar. En las entrevistas se presentan dos vertientes, por un lado, están las estrategias que son acciones probadas e instrumentadas por los docentes a lo largo de los años y, por otro, figuran las recomendaciones y sugerencias que son más bien posturas ante el fenómeno. 


\section{Sugerencias y recomendaciones}

\section{I. El ejemplo como recurso educativo}

Un aspecto en que coinciden las entrevistas es la importancia que tiene el ejemplo cotidiano que dan los docentes frente a los alumnos: predicar con el ejemplo es aún un referente importante para valorar el trabajo de muchos compañeros, como lo señala una maestra:

Maestra de Colima, 29 años, escuela secundaria pública, turno vespertino:

[...] no hay mejor dato que el trabajo cotidiano, ahí te puedes dar cuenta de que un maestro regaña, grita o pega, y todos sabemos que los alumnos son muy inteligentes y de todo se dan cuenta [...].

Otro testimonio de una maestra de primaria en el mismo sentido señala lo siguiente:

Maestra de Armería, 49 años, escuela primaria, turno matutino:

Es como el maestro que le dice a los alumnos que está prohibido usar el teléfono en la clase y él se la pasa contestando o hablando por teléfono ¿̇no? [...].

\subsection{Contar con personal especializado}

Otra coincidencia en las entrevistas fue señalar que la Secretaría de Educación debería contar con personal especializado por escuela, es decir, médicos, psicólogos y especialistas en el manejo de conflictos en los planteles, pues, a veces, los maestros no saben a dónde recurrir y canalizar los casos que se presentan, así lo visualiza una maestra:

Maestra de Colima, 36 años, secundaria pública turno matutino:

Yo trabajé en un colegio (escuela particular) y lo bueno de ahí es que había un problema y luego, luego lo atendían, la psicóloga hablaba con los padres y todo era muy rápido, y también había un joven [...], se podía acercar a los alumnos y nos contaba de sus preocupaciones, eso servía de mucho [...].

Además de médicos y psicólogos la propuesta señala la presencia de un intermediario, lo que se conoce en algunos países como animador escolar, y que funge como mediador institucional de los distintos conflictos que surgen.

\subsection{La necesaria presencia de los padres}

Desde diferentes posiciones y pronunciamientos, una coincidencia relevante es que el problema de la violencia en la escuela no se puede resolver sólo con la participación de los maestros y desde la escuela solamente, es necesaria la inclusión de los padres de familia, así lo señala el siguiente testimonio:

Maestra de Colima, 32 años, escuela primaria, turno matutino:

Sí es necesario que los padres entren a la escuela [...], no es fácil tenerlos aquí, y eso es un gran reto, pero si no son ellos, ¿entonces quién más? [...], también hay que 
decir que uno no sabe cómo hablarles, luego no quieren venir porque hasta dicen que uno los regaña.

La recomendación indica que se debe promover que los padres participen, y es requisito indispensable que se garantice un mecanismo de colaboración y comunicación entre escuela y familia.

\subsection{Reconocer que hay conflictos en la escuela}

En muchas de las escuelas de nuestro país la violencia todavía está muy lejos de ser un tema que pueda ser abordado ampliamente; sigue siendo un tabú, tanto para padres, docentes y maestros. Hablar de violencia resulta incómodo y no sólo para la víctima, sino también para quien la ejerce. Por esta razón es que en ocasiones es difícil detectarla a tiempo, pues se oculta hasta que ya es muy intensa o de plano los efectos son muy notorios e irreversibles.

\subsection{Buenos cursos de capacitación}

Los profesores están acostumbrados a asistir a distintos cursos de actualización a lo largo del año escolar, sin embargo, existe el señalamiento de que deben tener una aplicación práctica.

Maestra de Villa de Álvarez, 4I años, escuela pública, secundaria turno matutino:

No tengo nada en contra de los cursos, son buenos y eso es algo que debería de apoyarse, pero me ha tocado que va un representante y lo que [nos] explica no es lo mismo $[\ldots]$.

Durante la investigación se indagó sobre los temas que las docentes requieren como urgentes para afrontar un tema como la violencia, mencionaron: el manejo del conflicto, estrategias de pacificación; consejos para mejorar el ambiente en el aula; sugerencias para mejorar la comunicación con los padres de familia; indicadores para detectar el bullying; y recomendaciones y recursos didácticos para los alumnos. Pero además, solicitaron que los cursos fueran permanentes, más allá de cualquier coyuntura, y acordes con el contexto de Colima.

\subsection{La violencia es algo con lo que tenemos que aprender a vivir, ¿̇qué hacer?}

Un aspecto que preocupa mucho a los docentes es el tema de la seguridad en los planteles y sus alrededores, pues el fenómeno de la violencia si bien no ha llegado a Colima como en otros estados de la república, es un asunto que está por atenderse en los términos que señala una maestra de Comala:

Yo no sé cómo reaccionaría si pasara una balacera por ejemplo [...], mi marido me dijo que apunte los teléfonos de seguridad, de la policía, pero hace falta saber ¿qué hacer? [...]. 


\subsection{Probibido tocar a una mujer}

Intentar modificar los patrones tradicionales de los niños tiene su costo, por ejemplo, en el caso de las niñas que ya no adoptan una posición pasiva ante sus compañeros varones, las situaciones se tornan conflictivas, porque los niños ejercen más violencia física para poder mantener el control, por ejemplo, un alumno entrevistado señaló lo siguiente:

Las niñas se ponen al brinco y unas son más pegonas [...], ya no se dejan, y se arman unos broncones, ayer el chino le dio trancazos a una grandota y la grandota le dio un golpazo en la cabeza, ¡hasta lo tiró!

Ante esta situación, los docentes entrevistados señalan que las niñas que «ya no se dejan» son llamadas marimachas u hombrunas, cuando lo que sucede es que "ya se cansaron de sufrir burlas y desprecios», como lo señala la maestra de Villa de Álvarez:

Aquí es todo un show, porque las niñas ya se cansaron de sufrir burlas y desprecios, se ponen al tú por tú a los niños y a éstos no les gusta que eso pase, porque ya no se dejan $[\ldots]$, resulta que por defender sus derechos sufren más violencia $[\ldots]$.

La maestra señala que la estrategia que ella ha implementado la ha denominado: Probibido tocar a una mujer, el argumento es el siguiente:

Yo no tolero el maltrato a las mujeres, y es que a mí me maltrataba mi marido hasta que lo dejé [...] sé que hay mucho de esto en casa de los niños, pero aquí no, ¡eso sí que no!, y por eso lo de prohibido tocar a una mujer, se tienen que enseñar a respetar, si no es aquí ¿en dónde? [...] el castigo es hablar con los padres y si no pido expulsión de mi grupo [...].

\subsection{Llamar a los padres a la escuela}

En opinión de las maestras una de las primeras acciones deseables es «reeducar»a los padres, al menos así lo expresaron tres docentes que se pusieron de acuerdo y realizaron reuniones con padres para hablar de problemas de drogadicción y disciplina, el resultado obtenido fue importante, así lo refiere una de ellas:

[...] nos abrió la puerta conocer a los padres y sirvió, ahora estamos preocupadas por saber del tema, nos dimos cuenta de que nos hace falta [...] saber más, porque créeme que los padres lo necesitan, hasta recuerdo que unos nos dijeron estar desesperados y no saber ¿cómo entrarle? [...], así de grave.

No hay una comunicación lo suficientemente efectiva entre la escuela y las familias, y lo más importante es que muchos padres y maestros tienen dificultades para comprender qué es lo que pasa con sus hijos. Es importante señalar que es un tema delicado, pues no en todos los casos los padres reciben de buena forma los comentarios, por ejemplo, el siguiente testimonio:

[...] la madre llegó con una actitud desafiante [...], muy agresiva hacia la escuela y hacia la institución [...], a veces con palabras altisonantes se dirigen a una. 
5.9. Todos le vamos a preguntar ¿por qué pega?

Es imposible encontrar un aula exenta de conflictos. De distinta índole y magnitud, pero siempre hay quien encabeza actitudes de indisciplina y/o violencia, tal y como lo refiere el siguiente testimonio:

Maestra de Colima, 37 años, escuela primaria pública, turno vespertino:

[...] tenía un niño que en cuanto me volteaba escupía a los niños, los golpeaba [...], me agarraba a las niñas atrás de los salones y les pegaba en el estómago o las pateaba, les jalaba el pelo, les rompía las libretas [...] tenía su banda, se aventaban papeles [...] en el mismo salón [...], yo no sabía qué hacer, ni cómo hacer [...] a diario regañarlos, regañarlos y [...] una vez lo cambié de lugar, me acuerdo que me dijo: -No quiero. Le dije: -Sí te vas a cambiar y te vas a cambiar. Me respondió: -No, y si me obliga ¡la voy a demandar!

El testimonio señala uno de los aspectos más sensibles hacia los maestros: el de las quejas y demandas por maltratar a un alumno. Por esta razón, la estrategia es que entre todos hablen y le recuerden al agresor que su forma de proceder está mal.

\subsection{Si el maestro pega, no lo hará si lo vigilan}

En las entrevistas se señaló que la violencia la ejercen algunos maestros, lo cual es inaceptable si se quiere cambiar la dinámica de la violencia y erradicarla de las aulas. Un grupo de maestras de Villa de Álvarez sugieren una estrategia que involucra la participación de alumnos de las escuelas normales y de pedagogía para que acompañen a los docentes al dar sus clases, en particular a los que tienen fama de «mano larga»:

Hay maestros que con el gis, borrador y hasta con los libros les dan a los alumnos, no nos hagamos tarugos, ¡sí los hay!, pero ¿por qué no ponerles a alguien que los acompañe cuando den clase?, que los cuide, porque nosotras no podemos decirles porque hasta se molestan [...]. Hay muchos alumnos de la normal y de pedagogía que les serviría estar con un maestro en servicio [...].

La idea de supervisión es algo que debería retomarse, pues la dinámica cotidiana cambiaría significativamente, incluso siendo optimista, podría ser un espacio de formación importante para los estudiantes de la Escuela Normal.

\section{II. La asamblea semanal y el tema de la conducta}

Un problema severo en las escuelas es, sin duda, la ausencia de denuncia entre alumnos que ejercen violencia, ya sea de forma esporádica o reiteradamente. Desde luego que el temor a las represalias o ser tildado de soplón son factores explicativos. Ante esta situación, una profesora de Manzanillo sugiere implementar la Asamblea semanal de la conducta, con la finalidad de remediar grupalmente los conflictos, la idea es la siguiente:

Maestra de Manzanillo, 39 años, escuela primaria, turno vespertino:

Un día a la semana es necesario reunirse para platicar con los alumnos y abordar lo que se tenga que decir, ¿quién se portó mal?, ¿quién salió castigado?, ¿a quién lo están 
molestando?, ¿quién se siente con miedo? Porque yo creo que muchos no se atreven a decirlo, por eso en grupo es mejor, además uno como maestro ya sabe ¿quién es quién?

La ventaja de estos espacios es que temas delicados como la disciplina, la violencia, la amenaza, entre otros, pueden ser abordados y dirigidos reflexivamente en conjunto por el docente.

\section{I2. Tareas parejas para todos en el salón}

Esta estrategia señala, según la maestra de Villa de Álvarez, para quitar prejuicios y estereotipos en los roles, y básicamente se enfoca a que los niños lleven a cabo acciones que, por lo regular, no están familiarizados a realizar:

Aquí en el salón hemos hecho el propósito de mantenerlo limpio [...], los viernes hacemos el aseo, y eso sí, a propósito pongo a los niños a trapear, limpiar y lavar los trapos y trastos [...], esto no tiene mucha importancia dirás, pero sí la tiene [...], para que se den cuenta de que no son cosa de mujeres solamente.

\subsection{Psicólogos en lugar de prefectos}

Esta propuesta de una maestra de Villa de Álvarez se enfoca en incorporar más personal en la escuela, pero con una función específica que atienda problemas de índole psicológica, pues en su opinión gran parte de los problemas de los alumnos de secundaria está en la falta de atención en sus hogares y problemas de soledad, así lo señala:

Yo creo que el verdadero problema está en que los muchachos tienen muchos, pero muchos problemas de atención, van cargando muchos problemas, muchos traumas y en su casa ni los pelan, ni les hacen caso [...], yo sí cambiaría a los prefectos por personas que sepan de psicología, y de cómo atender a los alumnos, pero ya ve, en las escuelas hay mucha gente que no hace nada y ahí sigue.

La figura de los prefectos data de hace muchos años, surgió en los cuarenta, pero actualmente es poco claro el papel que deben desempeñar al interior de los planteles, incluso en algunos testimonios emitidos por los alumnos señalan que más bien desempeñan funciones de «celadores y cuidadores», pero casi nunca reciben una orientación académica de su parte.

\section{I4. Sobre los más latosos hay que enfocarse}

De acuerdo con un maestro, los años de experiencia le han enseñado que es mejor centrarse en determinados alumnos al principio para evitar conflictos posteriormente:

Maestro de Colima, 48 años, escuela particular, turno matutino:

[...] no te niego que uno se harta a veces, yo por eso digo que es mejor detectar desde un principio a aquellos alumnos que son más latosos, más inquietos y te los sientas junto 
a ti y los estás vigilando, a mí me ha servido, no hay otra, porque de verdad se contagia eso de portarse mal [...].

Esta estrategia coincide con la opinión de otros profesores; el problema como lo manifestaron es que por lo regular no se pone más atención en aquellos alumnos que no dan problemas, aunque con los que «más batallan son con los latosos», como se muestra en la siguiente entrevista:

Maestra de Tecomán, 38 años, escuela secundaria, turno matutino:

Es que se les pega lo de portarse mal, como que se ponen de acuerdo y siempre una más batalla con los latosos, y los que se portan bien [...] como te ponen más atención hasta con ellos te apoyas, pero [...] son los que menos necesitan $[\ldots]$.

\subsection{Las clases deberian de impartirse con dos profesores}

La profesora de Colima señala que sería muy bueno que dos maestras atendieran el grupo, porque en su opinión: « [...] los alumnos van a poner atención, se guardaría el orden, y que algo pasa mientras estás ocupada pues ahí está tu compañera para atender [...] al ser más maestros en todos los espacios, todo mejoraría», así lo narra:

A veces están muy inquietos, más se ponen cuando vienen fiestas y actividades de grupo [...], y es que te descuidas y ya están aventándose [...], con un apoyo de otra compañera cambiaría, así si los alumnos van a poner atención, se guardaría el orden [...].

Vale la pena señalar que las quejas de algunos profesores está en que los grupos son muy grandes y requieren de ayuda para evaluar y dar seguimiento a algunas de las actividades de los alumnos. Desde luego que, como dijo una entrevistada, saldrá más caro pagar a más maestros, pero los beneficios a futuro serían mejores, así lo mencionó:

Maestra de Villa de Álvarez, 34 años, escuela secundaria, turno matutino:

Deberían de poner a más maestros, no que uno con grupos de 25 y hasta 35 jóvenes se vuelve una loca por momentos, y tratas de dar la clase y no se puede [...] yo ya dije que venga otra compañera y que ayude a lo administrativo, y a apoyar a los que se van quedando atrás, se necesita [...] sale más caro, pero sería mejor a futuro [...].

Esta idea requiere de la colaboración y coordinación entre los profesores, de tal manera que ambos puedan apoyarse para cumplir con las actividades de la clase.

\subsection{Agotarlos, cansarlos, hasta que no puedan más...}

En la opinión del docente de matemáticas, lo que se requiere para bajar los niveles de agresividad de los alumnos, a través de mantenerlos en actividad, lo propone de la siguiente manera:

Maestro de Colima, 39 años, escuela secundaria, turno vespertino:

Yo sí creo que hay mucha violencia, que hay unos alumnos más canijos que otros [...], están en una edad muy difícil, muchos traen problemas de su casa y nadie les ayuda, 
por eso, que lo saquen a deportes [...], corriendo, saltando, pero que se muevan [...], porque es la única manera [...] que se controlen, pero la verdad como está la secundaria no creo que lo hagan, los atiborran de materias [...].

\subsection{La lista de lo bueno, lo malo}

Esta estrategia expuesta por un maestro de Villa de Álvarez tiene como finalidad hacer que los alumnos expresen lo que les molesta, pero también de encontrar los principales problemas de convivencia en el salón de clase, a través de la voz de los alumnos, así lo contó:

Maestro de Villa de Álvarez, 42 años, escuela secundaria, turno matutino:

Yo les pido que a mitad de año, cuando ya se conocen, que hagan una lista de lo que les gusta, de cómo les gustaría que los trataran y lo malo que les pasa [...]. Hay historias muy tristes [...] te puedo decir que sí sirve, y lo único que piden es respeto, sí, respeto es lo que todos buscan, pero muchas veces ¡no los oímos!

Un común denominador de las entrevistas es que los maestros sienten que los alumnos en sus casas no son atendidos y escuchados, y que si bien viven en familias señaladas como integradas, en el fondo, es sólo una apariencia pues los hijos no son tomados en cuenta.

\section{I8. Videos que toquen fibras y sentimientos}

En la perspectiva de esta profesora, lo que se debe tratar es de llegarles a los alumnos con mensajes positivos, videos que los hagan reflexionar, desde luego que la finalidad es lograr que la violencia sea erradicada y utilizar los videos para poder platicar en torno a temas sin que los alumnos se sientan ofendidos. De acuerdo con su testimonio, se requiere que el profesor tenga mucho material de donde echar mano, sin embargo, existen algunos inconvenientes relacionados con la forma en que está estructurada la jornada escolar en la secundaria:

Maestra de Villa de Álvarez, 26 años, escuela primaria, turno matutino:

Yo creo que en esta edad hay que entrarles por la buena, por la parte de la reflexión, de la buena onda, porque así no te metes en problemas, ponerles videos con mensaje [...], lo malo es que no hay tiempo, aquí andas apenas entrando a clase y ya te tienes que salir, hacen falta estos espacios para que los alumnos se puedan expresar libremente [...].

La profesora dijo que, a veces, es necesario darles un espacio para este tipo de actividades en beneficio de los alumnos, pero el plan de estudios no da mucho margen al respecto.

\subsection{Aprender a dialogar y a respetar los errores}

De acuerdo con la profesora, los alumnos no saben mostrar su enojo y mucho menos expresarlo, además, señala que hay que enseñarles a no tomarse todo personal, 
porque eso trae como consecuencia un ambiente tenso en el salón, por ejemplo, señala lo siguiente:

[...] parecen gallitos de pelea, nomás están esperando a que uno se equivoque al leer o al hacer una operación para empezarse a burlar, pero les digo que eso no es importante, trato de que eso que dicen no lo tomen de pretexto para empezar a pelearse [...] me ha tocado que aquí en pleno salón se han agarrado a golpes.

No saber cómo decir las cosas y, desde luego, saber mostrar su desacuerdo antes de entrar en contacto físico es una conducta muy difícil de enseñar, la profesora señala que la razón radica en que:

[...] en sus casas nadie les enseña cómo se deben pedir las cosas, los maltratan y los ofenden antes que pedirles por favor [...], hace falta educación de sus papás [...] te das cuenta porque cuando hablas con los papás en una junta o porque los llamas, algunos no saben más que ofender a su hijo delante de mí [...], ¿cómo le pido al alumno que cambie?

La propuesta se basa en que es necesario romper con el ciclo de desprecio-venganza, es decir, eliminar el problema de la comunicación y no generar más problemas, aunque como ella lo reconoce: «Está por demás difícil hacer que entiendan y no se golpeen».

\subsection{La valoración semanal de los alumnos}

Desde la perspectiva de esta maestra la explicación acerca de por qué se presentan los conflictos y la violencia en la escuela es porque «todo mundo está muy presionado en la secundaria», la intensa carga curricular, así lo explica:

Maestra, 45 años, Villa de Álvarez, escuela secundaria, turno matutino:

[...] yo la verdad a unos alumnos los veo muy preocupados por cumplir, unos cuántos ¡eh!, pero otros de plano no [...], ya no quieren cumplir y la presión es canija [...], para mí la violencia está en esto que te digo, todo mundo anda igual y la secundaria no les da espacio para hablar de cosas para su vida.

La iniciativa señala que es necesario hablar con los muchachos e invertir a la semana en un espacio con ellos, convivir profesores, personal de la Secretaría y padres, porque «es necesario conocer el problema de cerca»:

Maestra, 38 años, Villa de Álvarez, escuela secundaria, turno matutino:

Para como están las cosas, de verdad que se necesita mucha plática con los muchachos [...], es necesario conocer el problema de cerca y saber qué les molesta, pero con maestros de aquí, de la Secretaría y padres [...].

\section{Conclusiones}

La estrategia es un recurso de sobrevivencia en contra de la violencia escolar, pues es una forma de afrontar el fenómeno y poder llevar a cabo el trabajo docente. Las implicaciones de la violencia en la práctica son por demás preocupantes no sólo en 
términos de la transmisión de los contenidos o del control en el aula, sino también por las consecuencias que tiene para el maestro y que se traduce en un malestar e incomodidad al realizar su trabajo.

Esta investigación privilegió la búsqueda de las estrategias y acciones que los maestros realizan todos los días y que en algunas ocasiones ellos mismos no valoran en su justa dimensión, pues consideran que son irrelevantes o poco importantes porque no son dadas a conocer en un contexto más amplio, sin embargo, son recursos y herramientas centrales para el docente en su trabajo cotidiano.

Las estrategias implementadas ponen sobre la mesa un abanico interesante de recomendaciones que refieren no sólo sugerencias, sino también sobre el quehacer docente mismo y las particularidades que adopta en cada contexto.

Desde luego que es muy importante resaltar el hecho de que este conocimiento se va generando conforme se desarrolla su práctica. En otras palabras, es el resultado de las interacciones entre la experiencia y el lugar de trabajo que afronta el maestro, lo que hace particular esta parte es que se va desarrollando una personalidad y un estilo que le permite elegir algunas estrategias que considera como importantes para el cumplimiento de su actividad, situación que puede ser definida como un tipo de saber que es eminentemente empírico. Un conocimiento que tiene su origen en la práctica, es un saber hacer que no necesariamente tiene un origen en la teoría, aunque responda y retome algunos postulados de ella; se trata más bien de un saber que se alimenta, principalmente, de las posturas que el docente desarrolla y va aprendiendo de las concepciones sobre la enseñanza y el aprendizaje que el docente conoce en las instituciones educativas en donde trabaja y de igual forma de sus compañeros, es decir, de los principios, reglas, rutinas que cada profesor desarrolla en su lugar de trabajo: el aula.

Ante la urgente demanda y presión de la actividad docente, los profesores se ven obligados a implementar recursos sin conocer explícitamente los supuestos pedagógicos y didácticos en que se sustentan, sin embargo, tampoco hay tiempo y espacios para reflexionar en torno a lo implementado, esto explica, por una parte, que muchas de las estrategias no se socialicen o lleguen a un público más amplio y, por otra, que no sean valorados como recursos útiles por los mismos docentes. Sin embargo, es importante señalar que para algunos docentes prevalece la idea del castigo como estrategia, pero fueron pocas las opiniones en este sentido.

Un aspecto que debe valorarse es que existe un discurso en contra de la violencia en sus distintos niveles, más allá de que los profesores señalen o cuenten con una definición en específico, sin embargo, reconocen que es un tema que les preocupa y que les quita mucho de su tiempo para poder organizar e impartir su clase.

La violencia en la concepción de los profesores entrevistados se asocia con los siguientes aspectos: a) factores propios de la edad de los alumnos; b) ausencia de personal calificado; c) el factor familiar y la mala educación recibida; d) los maestros no saben cuándo un alumno presenta problemas psicológicos o físicos que lo motiven a desarrollar actos de violencia en contra de sus compañeros o de sus profesores; e) el lugar de socialización de los jóvenes: la colonia, el barrio y los amigos son determinantes; f) los maestros señalan que se debe a la cultura que prevalece en nuestro país, que se caracteriza por el autoritarismo y el poco diálogo que existe entre los sujetos en conflicto; g) se señala insistentemente que desde los hogares la interacción es violenta, y forma parte de una cultura machista que se reproduce en la escuela y es necesario modificar para combatir la violencia. 


\section{Bibliografía}

Anderson, J. (1962) Studies in Empirical Philosophy. Sydney: Angus y Robertson.

BALl, S. (1989) La micropolítica de la escuela. Hacia una teoría de la organización escolar. Barcelona: Paidós-MEc.

Cohen, L.; Manion, L. y Morrison, K. (20II) Research methods in education. Routledge: New York.

Contreras, R. (20I3) El concepto de estrategia como fundamento de la planeación estratégica. Pensamiento y Gestión, 35, I52-18I.

Elbaz, F. (I988) Cuestiones en el estudio del conocimiento de los profesores. En L. Villar ANGUlo (dir.) Conocimiento, creencias y teorias de los profesores (pp. I03-I25). España: Marfil.

Fernández, L. (1989) Instituciones educativas. Dinámicas institucionales en situaciones críticas. Buenos Aires: Paidós.

FERNÁNDEZ, L. (200I) El análisis de lo institucional en la escuela. Un aporte a la formación autogestionaria para el uso de los enfoques institucionales. Buenos Aires: Paidós.

Francés, A. (2006) Estrategia y planes para la empresa: Con el cuadro de mando integral. México: Pearson Prentice Hall.

Furlan, A. y SpItzer, T. (20I3) Estado de conocimiento área I7: Convivencia, disciplina y violencia en las escuelas. México: ANuies.

GeERTZ, C. (2006) La interpretación de las culturas. Barcelona: Gedisa.

Gómez-Nashiki, A. (2005) Violencia e institución educativa. Revista Mexicana de Investigación Educativa, io (26), 693-718.

Gómez-Nashiki, A. (2008) La práctica docente y el fomento de la lectura en Colima: Estrategias y recomendaciones de los docentes de educación básica. Revista Mexicana de Investigación Educativa, 13 (39), IOI7-I053.

Gómez-Nashiki, A. (20I3) Bullying. El poder de la violencia. Revista Mexicana de Investigación Educativa, I8 (58), 839-870.

Gómez-Nashiki, A.; Zurita, Ú. y López, S. (2013) La violencia escolar en México. México: Cal y arena, Sistema Nacional de Educación a Distancia, Universidad de Colima.

Hammersley, M. y Atkinson, P. (1994) Etnografía. Métodos de investigación. Barcelona: Paidós. Jackson, Ph. (200I) La vida en las aulas. Madrid: Morata.

KäEs, R. (1989) Realidad psíquica y sufrimiento en las instituciones. En R. KäEs, J. Bleger, E. Enríquez, F. Fornari, P. Fustier, R. Rousillon y J. P. Vidal (eds.) La institución y las instituciones. Estudios psicoanalíticos (pp. 15-3I). Buenos Aires: Paidós.

Mercado, R. (2002) Los saberes docentes como construcción social. La enseñanza centrada en los niños. México: FCE.

PÉRez, A. (1999) La cultura escolar en la sociedad neoliberal. Madrid: Morata.

Ricoeur, P. (2007) Tiempo y narración. Configuración del tiempo en el relato histórico. México: Siglo XXI Editores.

Rockwell, E. y Mercado R. (2003) La escuela, lugar del trabajo docente. Descripciones y debates. México: DIE-CINVESTAv.

Welzer-LANG, D. (2007) La violencia doméstica a través de 60 preguntas y 59 respuestas. Madrid: Alianza editorial.

Willis, P. (1998) Aprendiendo a trabajar. Cómo los chicos de la clase obrera consiguen trabajos de clase obrera. Madrid: Akal. 